\title{
Los modelos de descentralización educativa en América Latina
}

\section{Emanuela Di Gropello}

Oficial de Asuntos

Económicos, CEPAL
La descentralización de los servicios sociales es un eje esencial de las reformas de política social que se están efectuando en América Latina para hacer más eficiente la provisión de estos servicios y fortalecer los procesos de democratización. Aquí se analizan los procesos de descentralización de la educación en siete países latinoamericanos (Argentina, Bolivia, Brasil, Chile, Colombia, México y Nicaragua). Se intenta sistematizar estas experiencias, utilizando una tipología teórica de modelos de reforma; mostrar algunos resultados y tendencias en cuanto a eficiencia y equidad de la provisión de los servicios, y extraer algunas enseñanzas para el diseño de futuras reformas. Aunque los modelos desarrollados en los distintos países son diversos, tienen algunos elementos comunes: dependencia de los recursos del nivel central para financiar los servicios, y, en muchos casos, subordinación de la escuela a decisiones tomadas a otros niveles. Entre los efectos económicos y sociales de las reformas, sobresalen los avances limitados en participación y, por ende, eficiencia social, y ambiguos en materia de eficiencia técnica, así como una tendencia aún poco comprobada a mayores disparidades interterritoriales de los indicadores educativos. Entre las enseñanzas de política, destaca la importancia de entregar alguna autonomía real a los nuevos niveles proveedores, utilizar un sistema de transferencias que incentive la búsqueda de la eficiencia y a la vez preserve la equidad, cuidar la coherencia interna de los modelos, entregar algunas responsabilidades directamente a las escuelas y contar con un marco para la regulación y supervisión de los sistemas proveedores de servicios descentralizados. 


\section{I}

\section{Introducción}

Las reformas estructurales llevadas a cabo en América Latina durante los años ochenta con miras a modificar el papel del Estado en la economía, y la incorporación de los equilibrios macroeconómicos como elemento central de la política económica después de la crisis de comienzos de los años ochenta, condujeron a una nueva concepción de la política pública y particularmente de la social. La concepción paternalista del Estado, que había llevado a medir los resultados de las políticas en términos cuantitativos, ha sido sustituida gradualmente por un enfoque que privilegia objetivos de calidad, eficiencia y selectividad del gasto público. Los procesos de privatización y descentralización de los servicios sociales que se están difundiendo en América Latina se ajustan perfectamente a este nuevo enfoque, por cuanto apuntan a mejorar la eficiencia de la provisión de dichos servicios.

Aquí nos concentraremos en los procesos de descentralización de la educación básica que están teniendo lugar en siete países de América Latina (Argentina, Bolivia, Brasil, Chile, Colombia, México y Nicaragua).

\section{II}

\section{Marco analítico}

El análisis de la lógica y consecuencias de la descentralización es complejo, por la variedad de conceptos que una reforma de este tipo implica. Según Rondinelli, Nellis y Cheema (1983), la descentralización puede ser definida como la transferencia de responsabilidades en la planificación, gestión, obtención y distribución de recursos, desde el gobierno central y sus organismos hacia las unidades en el terreno de organismos gubernamentales, unidades o niveles subordinados del gobierno, autoridades o corporaciones públicas semiautónomas de mayor presencia, autoridades regionales o funcionales, u organizaciones no gubernamentales privadas y voluntarias. Con referencia a esta última categoría de instituciones, la descentralización puede definirse también como una situación en la cual los bienes y servicios públicos son provistos por el mercado, respondiendo a las preferencias manifiestas de
El análisis de estos procesos se dificulta por su complejidad. En efecto, la descentralización promueve una nueva distribución de papeles y poderes entre los actores institucionales preexistentes, de tipo territorial o no territorial, y trae consigo modificaciones profundas en el ámbito político-institucional, financiero, de la participación comunitaria, y otros. Para captar las características principales de esta nueva distribución de responsabilidades hemos introducido un marco conceptual que, además, ayuda a comparar los procesos de los distintos países. Nuestro propósito principal es describir y sistematizar los modelos de descentralización predominantes en los siete países, utilizando este marco de análisis. Intentaremos también mostrar de manera muy sintética algunos efectos de las reformas sobre la eficiencia y la equidad en la provisión de los servicios - cuyo mejoramiento constituye el mayor desafío del sector educativo en América Latina- y extraer algunas lecciones útiles para el diseño de futuros modelos de reforma. los individuos; en otras palabras, la privatización puede ser vista como una forma de descentralización. Dentro de este amplio espectro, aquí sólo se considerarán los casos de transferencia de responsabilidades desde el gobierno central a las unidades públicas subordinadas, y a corporaciones o autoridades públicas semiautónomas o autónomas.

Esta definición, sin embargo, aún encubre muchas formas posibles de descentralización. En general, las publicaciones ${ }^{1}$ sobre la materia distinguen tres formas principales, que se diferencian principalmente por el grado de autonomía en la toma de decisiones que el gobierno central otorga a las unidades subnacionales. En la práctica, sin embargo, no es fácil identificar las

1 Véase Rondinelli, Nellis y Cheema (1983), Klugman (1994) y Winkler (1991). 
experiencias reales con alguna de estas tres formas organizacionales, ya que la mayoría de dichas experiencias corresponde a tipos híbridos que combinan elementos de por lo menos dos de las tres formas de descentralización siguientes:

i) Desconcentración, que es el traspaso de responsabilidades a los niveles menores dentro de los ministerios u organismos del gobierno central, con poder de decisión limitado.

ii) Delegación, que consiste en la transferencia de responsabilidades de gestión en ciertas funciones específicamente definidas, a organizaciones públicas que pueden estar situadas fuera de la estructura burocrática normal del gobierno central (empresas públicas, empresas privadas reguladas por el sector público, autoridades a cargo del desarrollo de áreas y de planificación regional, etc.), por lo general con autoridad semiindependiente para ejecutar las tareas.

iii) Una forma de "devolución", ${ }^{2}$ que consiste en la transferencia de responsabilidades de gestión a las unidades subnacionales de gobierno o unidades públicas en general, claramente percibidas como niveles separados sobre los cuales las autoridades centrales ejercen poco o ningún control directo, es decir, con autoridad independiente para ejecutar sus actividades.

Ahora bien, se supone que una reforma descentralizadora de los servicios sociales debería mejorar la eficiencia del gasto público, por su impacto sobre los costos y los resultados de la prestación de dichos servicios. Los costos de producción podrían reducirse, por ejemplo, haciendo uso más intensivo de los recursos humanos y materiales de origen local y dando pie a un mayor control de los usuarios sobre la gestión del servicio, con lo cual aumentaría la eficiencia técnica (o productiva) de la provisión. ${ }^{3}$ La reforma debería llevar a una gestión más flexible y más cercana a las necesidades y preferencias locales, que mejoraría el rendimiento de los servicios y actuaría tanto sobre la eficiencia técnica ${ }^{4}$ como sobre la eficiencia social ${ }^{5}$ de

\footnotetext{
${ }^{2}$ Del inglés devolution, que se refiere a una forma de descentralización con transferencia total de poder.

${ }^{3}$ Aunque descentralizar la provisión del gasto significa también perder economías de escala y arriesgarse a aumentar, por lo menos en una fase inicial, los gastos administrativos (necesarios para que los niveles proveedores puedan hacerse cargo efectivamente de sus nuevas competencias).

${ }^{4}$ Que se mide comparando costos y resultados.

${ }^{5}$ Un bien es socialmente eficiente si sus características reflejan las preferencias de la comunidad de usuarios. Un argumento sólido a favor de la descentralización puede afincarse en el terreno de la eficiencia social si las preferencias y necesidades locales se manifiestan efectivamente y se encuadran dentro de la combinación de resultados que desea la comunidad.
}

su provisión. En definitiva, la descentralización debería permitir avanzar hacia una asignación más eficiente de los recursos y favorecer así el crecimiento económico.

Las consideraciones anteriores parecerían apuntar a la elección de un modelo de descentralización que deje total autonomía a los niveles subnacionales en la provisión de los servicios sociales, para poder aprovechar al máximo las posibilidades de acrecentar la eficiencia técnica y social. Sin embargo, tratándose de bienes de alcance nacional, hay razones que justifican una entrega sólo parcial de autonomía a los entes subnacionales, así como la preferencia de los gobiernos por reformas intermedias (como la desconcentración o delegación de responsabilidades) e híbridas (como la «devolución» con limitaciones de autonomía) antes que por reformas más radicales. Estas razones se vinculan al hecho de que, en un contexto donde los objetivos y preferencias de las unidades subnacionales son por lo general diferentes a los del gobierno central, o no pueden implementarse con eficacia a nivel local, es útil que el nivel central mantenga abiertos canales de intervención para fomentar los intereses nacionales. Por ejemplo, es fácil prever que en condiciones de heterogeneidad de recursos humanos y financieros entre las distintas áreas geográficas, la descentralización acrecentará la inequidad territorial. Si el gobierno se preocupa por la equidad espacial porque busca un desarrollo geográfico equilibrado e integrado del país, que se vincula con la distribución individual de la riqueza, encontrará necesario acompañar el traspaso de responsabilidades con intervenciones compensatorias o redistributivas. Igualmente, la presencia de externalidades interjurisdiccionales en la producción de bienes públicos de esta índole justifica una intervención para lograr que ellos se ajusten a estándares mínimos. Asimismo, la capacidad técnica probablemente limitada de los niveles subnacionales y la poca participación de la comunidad en la toma de decisiones a nivel local pueden dar pie, por lo menos al comienzo, a una intervención activa del nivel central.

Las intervenciones del gobierno central pueden tomar distintas formas. Entre los instrumentos con que éste cuenta para tal fin, las transferencias intergubernamentales son, sin duda, los que tienen más potencialidades (recuadro 1). Otros son las restricciones directas a la autonomía a través, por ejemplo, de mandatos (directrices coercitivas), leyes y estatutos que regulan ciertas funciones como la obtención y la utilización de los recursos y la administración de los recursos humanos. 
Recuadro 1

Algunos INSTRUmentos DE INTERVENCIÓN QUE PUEDE UTILIZAR EL NIVEL CENTRAL

- Directrices, coercitivas o no, sobre calidad y cantidad mínima o uniforme de los servicios sociales provistos.

- Establecimiento, a través de mandatos, de un nivel obligatorio mínimo de gasto público per cápita en la provisión de los servicios sociales.

- Transferencias generales redistributivas para reducir la inequidad de los ingresos per cápita en los distritos.

- Transferencias generales para emparejar los términos en que las jurisdicciones locales pueden suministrar los servicios sociales. Un ejemplo clásico de estas subvenciones es aquella diseñada para permitir que la misma alícuota fiscal produzca el mismo nivel de servicios.

- Transferencias generales condicionadas al cumplimiento de un cierto nivel de provisión de los servicios sociales por la jurisdicción receptora.

- Transferencias específicas (para un sector de gasto específico) condicionadas al cumplimiento de un cierto nivel de provisión de los servicios sociales por la jurisdicción receptora.

Fuente: Elaboración propia basada en Winkler (1994).

De hecho, el desafío principal que enfrenta el gobierno central es lograr que las unidades a las que entrega nuevas responsabilidades alcancen con la mayor eficiencia posible objetivos congruentes con los intereses nacionales, maximizando así las ventajas esperadas de una reforma descentralizadora sin perder el control sobre los resultados. Este desafío puede ilustrarse con bastante claridad en el marco de un modelo principal/agente, en el cual el nivel central viene a ser el principal y los nuevos niveles proveedores, los agentes, que siguen respondiendo al principal por sus acciones. Este tipo de modelo permite analizar la naturaleza específica de la relación entre el centro y la periferia, dando cuenta de algunos de los problemas de incentivos que suelen afectar a esta relación, como los de selección adversa y de riesgo moral.

La existencia de información asimétrica en presencia de objetivos centrales y locales diferentes crea un problema llamado de selección adversa: ${ }^{6}$ los gobiernos subnacionales pueden engañar al gobierno central acerca de sus verdaderas preferencias y condiciones económicas, dando lugar así una distribución inequitativa e ineficiente de los recursos centrales. Por otro lado, la incertidumbre ante acontecimientos fortuitos que afectan el resultado final de cada área (fluctuaciones macroeconómicas, por ejemplo) y que no son predecibles por el gobierno central ni por el gobierno sub-

\footnotetext{
${ }^{6}$ Extensivamente analizado en Rasmusen (1989) y Kreps (1990).
}

nacional, ${ }^{7}$ ni observables ex post por el gobierno central, ${ }^{8}$ crea otro problema llamado de riesgo moral, ${ }^{9}$ que puede inducir a los gobiernos subnacionales a minimizar su esfuerzo en la realización de su tarea, alegando mala suerte. Estos dos problemas dificultan la intervención del principal, toda vez que para resolverlos es preciso preparar contratos óptimos ${ }^{10}$ costosos y difíciles de aplicar en la práctica. En esta situación, el principal puede escoger utilizar mecanismos que le permitan negociar contratos más favorables y simples. El mecanismo principal para disminuir el alcance de los dos problemas es el de aumentar la cantidad de información de que dispone el nivel central, a través de una mayor supervisión técnica, el fortalecimiento de las bases locales de información, el establecimiento de objetivos intermedios —más fáciles de seguir que los

\footnotetext{
${ }^{7} \mathrm{Si}$ el agente pudiera observar el estado del mundo antes que el acuerdo fuera decidido, eso sería otra vez un caso de selección adversa.

${ }^{8}$ En presencia de objetivos diferentes y bajo el supuesto de que el esfuerzo del agente de producir el resultado no es observable por el principal. Esto es muy plausible en vista de los problemas de seguimiento conectados a acciones realizadas por unidades externas dentro de áreas geográficas pequeñas.

9 Analizado extensivamente en Kreps (1990), Rasmusen (1989), Rees (1985 a y b) y Hart y Holmstrom (1987).

${ }^{10}$ Donde el monto de las transferencias dependa de las condiciones y preferencias iniciales de los agentes y del resultado final de la acción, de conformidad con relaciones no lineales complejas que lleven a los agentes a revelar la verdad (en el caso de la selección adversa) y a seleccionar el nivel de esfuerzo deseado por el principal (en el caso del riesgo moral).
} 
objetivos finales- o una mayor participación de la comunidad local en juzgar el comportamiento de la unidad subnacional. Alternativamente - por ejemplo, en situaciones de falta de habilidades técnicas del nivel central y de consenso sobre los objetivos nacionales entre éste y la comunidad-, el gobierno tal vez prefiera imponer restricciones directas a la autonomía de los niveles subnacionales, traspasando la responsabilidad sobre parte de las funciones, o sólo parcialmente por función, a través de mandatos, leyes y estatutos más o menos restrictivos. Por ende, es la combinación entre la necesidad de intervención del nivel central para proteger los intereses nacionales y las dificultades implícitas en estas intervenciones por la diferencia de objetivos y la asimetría de información entre agentes y principal, lo que explica el predominio de modelos de descentralización de los servicios sociales tendencialmente más débiles que radicales.

El grado de autonomía efectivamente otorgado a los niveles subnacionales en la provisión de los servicios variará según la frecuencia e intensidad de las restricciones directas, los incentivos al comportamiento $^{11} \mathrm{u}$ otro mecanismo de control. Por todo lo señalado, la tipología de modelos teóricos indicada al principio de esta sección es, sin embargo, demasiado restrictiva para tomar en cuenta debidamente estas diferencias. Con miras a facilitar una clasificación según el grado de autonomía e incorporar más explícitamente aspectos relacionados con la participación de la comunidad en las decisiones de provisión de servicios y el número de niveles receptores involucrados, se agregan en seguida dos nuevas categorías de modelos, ubicados entre los de "devolución" y de desconcentración; además, se introduce un cambio - efectuado a menudoen la definición de una tipología existente. La clasificación resultante quizás sea en cierto modo arbitraria, pero será útil para ordenar las diversas experiencias que se presentarán más adelante. En ella se introduce:

i) Una categoría de modelos principal/agente de intensidad débil, o sea, de "devolución" híbrida, que se refiere básicamente a una "devolución" en la cual el nivel central sigue financiando una parte importante de la provisión de servicios sociales, pero a la vez los niveles subnacionales tienen un grado de autonomía elevado o muy elevado en todas las principales funciones involucradas en la provisión. Se mantiene una relación, aunque leve, con el nivel central.

\footnotetext{
${ }^{11}$ Bajo la forma de transferencias financieras generales o específicas asignadas según criterios predeterminados o condicionadas a comportamientos del receptor.
}

ii) Una categoría de modelos principal/agente de intensidad media, en la cual los niveles subnacionales tienen un grado de independencia relativamente elevado en casi todas las principales funciones, pero siguen respondiendo en medida importante al nivel central por sus acciones, debido a una estructura de financiamiento muy dependiente de ese nivel y a la vinculación a normas e incentivos de cierta intensidad que él establece. Estos modelos se destacan por el difícil equilibrio entre autonomía y control que caracteriza la relación entre los actores centrales y subcentrales.

iii) Una categoría de modelos principal/agente de intensidad fuerte, o sea de desconcentración, que consideran la figura del traspaso de responsabilidades a niveles que se sitúan también fuera del ámbito del nivel central. Este tipo de modelo presenta muchas restricciones directas al poder de decisión traspasado.

Otros dos aspectos que habría que tomar en cuenta al caracterizar un proceso de descentralización son: el receptor último al que llegó la reforma (el nivel intermedio, ${ }^{12}$ el local ${ }^{13} \mathrm{o}$ la propia unidad productora de los servicios) y el grado de participación efectivamente alcanzado por la comunidad local en el proceso de toma de decisiones. Por ejemplo, una reforma que involucra la unidad productora de los servicios (establecimiento hospitalario, escuela) y la comunidad de usuarios, traspasándoles responsabilidad sustantiva en la toma de decisiones, tiene mayor profundidad que una reforma que se queda en un nivel de provisión más distante de los usuarios y que no crea los mecanismos necesarios (instancias de participación, utilización de subsidios a la demanda, etc.) para que éstos controlen la calidad del servicio entregado y manifiesten sus preferencias. Otro aspecto relevante es la existencia de más de un nivel subnacional encargado de proveer el servicio. ${ }^{14}$ En este caso, se plantean problemas de coordinación y de asignación de responsabilidades que es necesario tomar en cuenta.

En el marco del modelo principal/agente presentado más arriba, una reforma en la cual la responsabilidad principal por la provisión es atribuida conjuntamente a dos o más niveles subnacionales, que deben actuar de manera complementaria, se traduciría en un

\footnotetext{
${ }^{12}$ Que alude, en general, a estados (en países federales), provincias o departamentos.

${ }_{13}$ Que alude a los municipios.

${ }^{14}$ Se trata de casos de corresponsabilidad entre dos o más niveles. Esto no incluye una posible participación marginal de distintos niveles.
} 
modelo con un principal y dos o más agentes. ${ }^{15}$ En tanto que una reforma que otorga a la comunidad local un papel fundamental en las decisiones sobre la provisión de los servicios, como por ejemplo respecto a diversas combinaciones de gastos y nombramiento del personal directivo, se podría identificar con un modelo que involucra un agente y dos principales (el gobierno central y la comunidad). En el caso de que el nivel central entregue autonomía casi total a los niveles subnacionales en la provisión del servicio, conformando un modelo de "devolución", se tendría entonces un modelo en el cual el único principal viene a ser la comunidad, es decir, se trataría de un modelo de elección fiscal local.

\section{III}

\section{Los modelos de descentralización educativa}

La mayoría de los países latinoamericanos está en el proceso de descentralizar sus servicios de educación básica $^{16}$ o primaria. Algunos por motivaciones más bien políticas (legitimación del Estado, control de situaciones conflictivas, democratización), otros por consideraciones fiscales (reducción del tamaño de la administración central y de sus costos, fomento a procesos indirectos de privatización), otros por razones de eficiencia y otros, en fin, por una combinación de los motivos mencionados. Sin duda, se puede decir que la descentralización de los servicios educativos, así como la de la salud primaria, es una megatendencia que impera en la región.

El estado actual de la provisión de servicios educativos en los siete países que se analizan aquí es el resultado de reformas generalmente continuas en el tiempo y con trayectorias a menudo no lineales que han traspasado la responsabilidad de proveer tales servicios a niveles subnacionales de tipo territorial (niveles de gobierno intermedios o locales) o a unidades públicas no territoriales (establecimientos escolares). Entre las reformas hay algunas de primera generación, iniciadas en los años ochenta o incluso antes, y otras de segunda generación, adoptadas a principios de los noventa. En el cuadro 1 se presentan los episodios de descentralización de la educación analizados en cada país. Las diversas condiciones iniciales de carácter socioeconómico y político-institucional de cada país, así como las distintas motivaciones que dieron comienzo al proceso de reforma, han llevado a sistemas descentralizados

\footnotetext{
15 Entendidos como categorías de agentes. Por supuesto, en el marco de un proceso de descentralización, el modelo que se aplica involucra de todas maneras a múltiples agentes, con consecuencias sobre la intensidad de los problemas de incentivo y el diseño de los contratos de transferencia.

16 Por educación básica se entiende aquí educación primaria más secundaria.
}

que difieren en el grado de autonomía que entregan a los niveles subnacionales, territoriales e institucionales al traspasar responsabilidad, y en el grado de participación de la comunidad en la toma de decisiones.

La configuración actual, en esos tres niveles — subnacionales, territoriales e institucionales — de los sistemas descentralizados de provisión de servicios educativos en los países que examinamos se muestra en el gráfico 1. En él se consideran solamente los modelos y tendencias predominantes, dejando de lado fenómenos con escasa cobertura a nivel nacional.

Para poder medir efectivamente estas dimensiones, se ha dividido la provisión del servicio educativo en cuatro grandes áreas que resumen las funciones fundamentales involucradas en ella: i) la función de conducción, regulación y supervisión del sector; ii) la función de financiamiento; iii) la función de administración directa del servicio, que involucra tanto la gestión corriente, con énfasis en la política laboral, como la gestión de la inversión, y iv) la función denominada de programación, que se refiere al conjunto de las decisiones de contenido tomadas en el campo educativo, en especial las que se refieren a metas educacionales y los aspectos pedagógico-curriculares de la enseñanza (establecimiento de la jornada y calendario escolares, de las metas específicas de cobertura y calidad, del currículo de estudio, etc.).

Las secciones $A$ a $G^{17}$ del gráfico 1 resumen, para cada uno de los países analizados, la participación del nivel central, de los niveles subnacionales - que incluyen el nivel intermedio, el nivel local y el establecimiento escolar (unidad de producción)—, así como de la comunidad, a través de organizaciones comunitarias o de usuarios, en la responsabilidad por estas dis-

${ }^{17}$ Versión resumida y simplificada de los cuadros presentados en Di Gropello (1997). 
CUADRO 1

América Latina (siete países): Algunos episodios de descentralización de la educación

\begin{tabular}{|c|c|c|}
\hline País & Inicio & Descripción del episodio \\
\hline Argentina & 1978 & $\begin{array}{l}\text { Traspaso de la responsabilidad de gestión de los establecimientos de educación primaria a las provincias. } \\
\text { Traspaso de la responsabilidad de gestión de los establecimientos de educación secundaria a las provin- } \\
\text { cias. }\end{array}$ \\
\hline Bolivia & 1994 & $\begin{array}{l}\text { La Ley de Participación Popular, promulgada en 1994, y la Ley de Descentralización Administrativa de } \\
1995 \text { traspasan, respectivamente, la infraestructura fisica de la educación básica a los municipios y la } \\
\text { responsabilidad de la administración de los recursos humanos y de la planificación a los departamentos. }\end{array}$ \\
\hline Brasil & $\begin{array}{l}\text { Sin fecha } \\
\text { precisa }\end{array}$ & $\begin{array}{l}\text { Los sistemas estaduales y municipales de educación primaria existen formalmente desde } 1930 \text {. A partir } \\
\text { de } 1970 \text { se intensifica la municipalización de la educación primaria y desde la mitad de los años ochenta } \\
\text { se profundiza la autonomía escolar en cerca del } 50 \% \text { de los estados. }\end{array}$ \\
\hline Chile & 1981 & Traspaso de la responsabilidad de gestión de los establecimientos de educación básica a los municipios. \\
\hline Colombia & 1991 & $\begin{array}{l}\text { Con la Constitución de } 1991 \text {, se traspasa a los departamentos la responsabilidad principal de la planifi- } \\
\text { cación y administración de los recursos humanos de educación básica y los municipios quedan responsa- } \\
\text { bles de la infraestructura física de las escuelas. }\end{array}$ \\
\hline México & 1992 & Traspaso de la responsabilidad de gestión de los establecimientos de educación básica a los estados. \\
\hline Nicaragua & 1993 & $\begin{array}{l}\text { Creación de los "centros autónomos" de educación primaria y secundaria, a los cuales se traspasan res- } \\
\text { ponsabilidades amplias de provisión del servicio. En } 1997 \text {, el proceso alcanza el } 50 \% \text { de los centros de } \\
\text { educación secundaria y el } 13 \% \text { de los centros de educación primaria. }\end{array}$ \\
\hline
\end{tabular}

Fuente: Elaboración propia.

tintas funciones. Esta síntesis no sólo permite identificar los niveles receptores de las funciones traspasadas $\mathrm{y}$ verificar si se trata de procesos que dejan espacio a la comunidad en la toma de decisiones, sino que al mostrar el número de niveles involucrados en cada una de las funciones permite establecer el grado de concentración de la responsabilidad por cada función; constituye así una indicación, aunque sólo parcial, del grado de autonomía de los niveles subnacionales en la provisión del servicio educativo. Para efectuar una evaluación exhaustiva del grado de autonomía entregado es preciso completar esta información con datos detallados acerca del papel de cada uno de los niveles en la función considerada, para determinar su importancia relativa en el proceso de toma de decisiones. Por ejemplo, el grado de autonomía del nivel local en el financiamiento del servicio depende no sólo de la participación de otros niveles en esta función, sino también del peso de los recursos propios (del nivel local) respecto de los recursos que provienen de otros niveles, del grado de descentralización de la ejecución del gasto $^{18} \mathrm{y}$, factor importante, de las condiciones de uso

\footnotetext{
${ }^{18}$ Los recursos propios pueden representar solamente una pequeña fracción de los recursos totales, pero la mayoría de éstos pueden haber sido traspasados al nivel local para su gestión.
}

de los recursos traspasados para la ejecución. Igualmente, en lo que se refiere a la administración de los recursos humanos, será distinto el grado de autonomía del nivel subnacional si está totalmente descentralizada la subfunción de contratación y sólo la negociación salarial queda centralizada, o si sigue parcialmente centralizada la contratación misma.

El cuadro 2 entrega información sobre la estructura del financiamiento y la gestión de los recursos humanos, las dos funciones que más se diferencian de un país a otro por grado de autonomía entregado. Las decisiones sobre los contenidos educativos son habitualmente compartidas por los diversos niveles, siendo el nivel central el que fija normas y planes generales de estudio más o menos flexibles, complementados por normas y planes originados por los niveles subnacionales. En Argentina, Brasil y Colombia la flexibilidad de los niveles subnacionales es mayor, pues sólo existen algunas normas básicas vinculantes.

Al observar los modelos presentados en el gráfico 1 se advierte una gran heterogeneidad de niveles involucrados en las distintas funciones que componen la provisión del servicio. En todos los casos, ${ }^{19}$ partici-

\footnotetext{
${ }^{19}$ Con la excepción de Argentina en la función de administración de los recursos humanos.
} 
América Latina (siete países): Síntesis de los modelos y tendencias que predominan en la descentralización de la educación ${ }^{a}$

A. Argentina

\begin{tabular}{|l|l|l|l|l|l|}
\hline \multirow{2}{*}{$\mathrm{N}$} & \multirow{2}{*}{$\mathrm{C}, \mathrm{R}, \mathrm{S}$} & \multirow{2}{*}{$\mathrm{F}$} & \multicolumn{2}{|c|}{$\mathrm{A}$} & \multirow{2}{*}{$\mathrm{P}$} \\
\cline { 4 - 5 } & & & $\mathrm{RH}$ & $\mathrm{O}$ & \\
\hline $\mathrm{NC}$ & & & & & \\
\hline $\mathrm{NI}$ & & & & & \\
\hline $\mathrm{NL}$ & & & & & \\
\hline $\mathrm{UP}$ & & & & & \\
\hline $\mathrm{C}$ & $\mathrm{T}$ & & & & $\mathrm{T}$ \\
\hline
\end{tabular}

C. Brasil

\begin{tabular}{|l|c|c|c|c|c|}
\hline & \multirow{2}{*}{$\mathrm{C}, \mathrm{R}, \mathrm{S}$} & $\mathrm{F}$ & \multicolumn{2}{|c|}{$\mathrm{A}$} & \multirow{2}{*}{$\mathrm{P}$} \\
\cline { 4 - 5 } & & & $\mathrm{RH}$ & $\mathrm{O}$ & \\
\hline $\mathrm{NC}$ & & & $\mathrm{T}$ & & \\
\hline $\mathrm{NI}$ & & & & & \\
\hline $\mathrm{NL}$ & & & & & \\
\hline $\mathrm{UP}$ & & & & & \\
\hline $\mathrm{C}$ & $\mathrm{T}$ & & & & \\
\hline
\end{tabular}

E. Colombia

\begin{tabular}{|l|l|l|l|l|l|}
\hline & \multirow{2}{*}{$\mathrm{C}, \mathrm{R}, \mathrm{S}$} & \multirow{2}{*}{$\mathrm{F}$} & \multicolumn{2}{|c|}{$\mathrm{A}$} & \multirow{2}{*}{$\mathrm{P}$} \\
\cline { 4 - 5 } & & & $\mathrm{RH}$ & $\mathrm{O}$ & \\
\hline $\mathrm{NC}$ & & & & & \\
\hline $\mathrm{NI}$ & & & & & \\
\hline NL & & & & & \\
\hline $\mathrm{UP}$ & & & & $\mathrm{T}$ & \\
\hline $\mathrm{C}$ & $\mathrm{T}$ & & & $\mathrm{T}$ & \\
\hline
\end{tabular}

G. Nicaragua

\begin{tabular}{|l|l|l|l|l|l|}
\hline & \multirow{2}{*}{$\mathrm{C}, \mathrm{R}, \mathrm{S}$} & \multirow{2}{*}{$\mathrm{F}$} & \multicolumn{2}{|c|}{$\mathrm{A}$} & \multirow{2}{*}{$\mathrm{P}$} \\
\cline { 4 - 5 } & & & $\mathrm{RH}$ & $\mathrm{O}$ & \\
\hline $\mathrm{NC}$ & & & & & \\
\hline $\mathrm{NI}$ & & & & & \\
\hline $\mathrm{NL}$ & & & & & \\
\hline $\mathrm{UP}$ & & & & & \\
\hline $\mathrm{C}$ & & & & & \\
\hline
\end{tabular}

B. Bolivia

\begin{tabular}{|l|l|l|l|l|l|}
\hline & \multirow{2}{*}{$\mathrm{C}, \mathrm{R}, \mathrm{S}$} & \multirow{2}{*}{$\mathrm{F}$} & \multicolumn{2}{|c|}{$\mathrm{A}$} & \multirow{2}{*}{$\mathrm{P}$} \\
\cline { 4 - 5 } & & & $\mathrm{RH}$ & $\mathrm{O}$ & \\
\hline $\mathrm{NC}$ & & & & & \\
\hline $\mathrm{NI}$ & & & & & \\
\hline NL & & & & & \\
\hline UP & & & & & \\
\hline $\mathrm{C}$ & & & & & $\mathrm{T}$ \\
\hline
\end{tabular}

D. Chile

\begin{tabular}{|l|l|l|l|l|l|}
\hline \multirow{2}{*}{$\mathrm{N}$} & \multirow{2}{*}{$\mathrm{C}, \mathrm{R}, \mathrm{S}$} & $\mathrm{F}$ & \multicolumn{2}{|c|}{$\mathrm{A}$} & \multirow{2}{*}{$\mathrm{P}$} \\
\cline { 4 - 5 } & & & $\mathrm{RH}$ & $\mathrm{O}$ & \\
\hline $\mathrm{NC}$ & & & & & \\
\hline $\mathrm{NI}$ & & & & & \\
\hline NL & & & & & \\
\hline UP & & & & $\mathrm{T}$ & \\
\hline $\mathrm{C}$ & & & & $\mathrm{T}$ & \\
\hline
\end{tabular}

F. México

\begin{tabular}{|l|l|l|l|l|l|}
\hline \multirow{2}{*}{$\mathrm{N}$} & \multirow{2}{*}{$\mathrm{C}, \mathrm{R}, \mathrm{S}$} & $\mathrm{F}$ & \multicolumn{2}{|c|}{$\mathrm{A}$} & \multirow{2}{*}{$\mathrm{P}$} \\
\cline { 4 - 5 } & & & $\mathrm{RH}$ & $\mathrm{O}$ & \\
\hline $\mathrm{NC}$ & & & & & \\
\hline $\mathrm{NI}$ & & & & & \\
\hline NL & & & & & \\
\hline UP & & & & & \\
\hline C & & & & & \\
\hline
\end{tabular}

Fuente: Elaboración propia basada en Carciofi, ed. (1996), RuizMier y Giussani (1997), Draibe (1998), FUNDAP (1996), IPEA (1994), Espínola (1995), Chile, MINEDUC (1996 a y b), Vargas y Sarmiento (1997 a y b), Ornelas (1997), Castillo (1998), Banco Mundial (1996), Fiske (1996) y Hevia (1991).

a $\mathrm{NC}=$ Nivel central; NI=Nivel intermedio; $\mathrm{NL}=\mathrm{Nivel}$ local; $\mathrm{UP}=$ Unidad de producción; $\mathrm{C}=$ Comunidad; $\mathrm{C}, \mathrm{R}, \mathrm{S}=$ Conducción, regulación y supervisión; $\mathrm{F}=$ Financiamiento; $\mathrm{A}=$ Administración; $\mathrm{RH}=$ Recursos humanos; $\mathrm{O}=\mathrm{Otras}$ funciones administrativas (gestión corriente y de capital); P=Programación; T=Función teórica, aún no en práctica. 
CUADRO 2 América Latina (siete países): Características de los sistemas
descentralizados de provisión de la educación, según algunos indicadores

\begin{tabular}{|c|c|c|c|c|c|}
\hline \multirow[t]{2}{*}{ País } & \multicolumn{3}{|c|}{$\begin{array}{l}\text { Distribución territorial del } \\
\text { financiamiento del gasto } \\
\text { público en educación básica, } \\
\text { después de las transferencias } \\
\text { intergubernamentales }\end{array}$} & \multirow[t]{2}{*}{$\begin{array}{l}\text { Naturaleza de las transferencias } \\
\text { y criterios de asignación }\end{array}$} & \multirow[t]{2}{*}{$\begin{array}{c}\text { Grado de } \\
\text { descentralización } \\
\text { de la gestión de los } \\
\text { recursos humanos }\end{array}$} \\
\hline & $\mathrm{NC}^{\mathrm{a}}$ & $\mathrm{NI}^{\mathrm{a}}$ & $\mathbf{N L}^{\mathbf{a}}$ & & \\
\hline $\begin{array}{l}\text { Argentina } \\
\text { (a partir } \\
\text { de 1978) }\end{array}$ & 8 & $\begin{array}{c}92^{\mathrm{b}} \\
(1978- \\
1985)\end{array}$ & - & $\begin{array}{l}\text { Transferencias generales, vía coparticipación de impuestos, asignadas por } \\
\text { ley. }\end{array}$ & $\begin{array}{l}\text { Política laboral autónoma } \\
\text { (NI) }\end{array}$ \\
\hline $\begin{array}{l}\text { Bolivia } \\
\text { (a partir } \\
\text { de 1994) }\end{array}$ & 10 & $\begin{array}{c}90^{\mathrm{c}} \\
(1997)\end{array}$ & - & $\begin{array}{l}\text { Transferencias específicas a departamentos, con directrices de asignación } \\
\text { para gasto corriente. } \\
\text { Transferencias generales a departamentos y municipios vía coparticipación } \\
\text { de impuestos, asignadas según población. Desde 1996, los recursos desti- } \\
\text { nados a los municipios tienen una directriz de asignación para inversión (el } \\
85 \% \text { de los recursos de coparticipación debe ser asignado a inversión). }\end{array}$ & $\begin{array}{l}\text { Contratación descentraliza- } \\
\text { da }(\mathrm{NI}) \\
\text { Negociación salarial y ca- } \\
\text { rrera administrativa centra- } \\
\text { lizadas }\end{array}$ \\
\hline
\end{tabular}

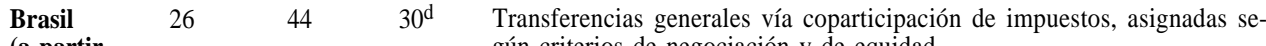
(a partir (1995) Transferencias específicas (salarios-educación) asignadas a los estados sesetenta) Transferencias específicas (salarios-educación) asignadas a los estados se-
gún lo recaudado. Desde 1995, el $60 \%$ del total de recursos para educación debe ir a un fondo que debe gastar por lo menos el $60 \%$ en remuneraciones. Los recursos provenientes del fondo son distribuidos entre las escuelas estaduales y municipales del Estado de acuerdo con el número de alumnos matriculados. Existe, además, una norma de gasto mínimo por municipio y, si el fondo no alcanza a cubrir este monto, la Unión debe pagar la diferencia con recursos propios. Este mecanismo es todavía teórico.

\begin{tabular}{|c|c|c|c|c|}
\hline $\begin{array}{l}\text { Chile } \\
\text { (a partir } \\
\text { de 1981) }\end{array}$ & 50 & - & $\begin{array}{c}50^{\mathrm{e}} \\
(1991)\end{array}$ & $\begin{array}{l}\text { Transferencias específicas, asignadas en relación con la tasa de asistencia me- } \\
\text { dia de los alumnos registrada en los últimos tres meses en cada municipio y } \\
\text { el costo de provisión del servicio. Existen también transferencias cruzadas } \\
\text { redistributivas entre municipios (a través del fondo común municipal). }\end{array}$ \\
\hline
\end{tabular}

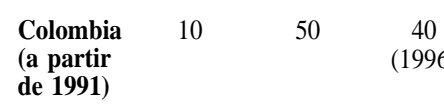

40 Transferencias generales a departamentos (Situado Fiscal), con directriz de asignación a salud (el 25\%) y educación (el 75\%), asignadas según gasto histórico, población y esfuerzo fiscal. En la práctica, según gasto histórico. Transferencia generales, vía coparticipación de impuestos, a municipios, con directiva de asignación ( $30 \%$ a educación) y asignadas según gasto histórico, indicadores de pobreza relativa local, esfuerzo fiscal y eficiencia administrativa. Fórmula demasiado compleja para ser eficaz.

$\begin{array}{lcccc}\begin{array}{l}\text { México } \\ \text { (a partir } \\ \text { de 1992) }\end{array} & 56 & 44^{\mathrm{f}} & - & \begin{array}{l}\text { Transferencias específicas asignadas de acuerdo con un monto irreductible } \\ \text { (que toma en cuenta lo asignado el año anterior) y a prioridades sectoriales. } \\ \text { Transferencias generales, vía coparticipación de impuestos, asignadas se- } \\ \text { gún población y recaudación histórica. }\end{array} \\ \begin{array}{l}\text { Nicaragua } \\ \text { (a partir } \\ \text { de 1993) }\end{array} & 68 & - & 32^{\mathrm{g}} & \begin{array}{l}\text { Las transferencias específicas a las escuelas, que antes se distribuían según } \\ \text { número de profesores, se asignan desde 1997 según el número de alumnos } \\ \text { atendidos, gasto administrativo y sueldos medios. Las transferencias espe- } \\ \text { cíficas a los municipios, que se introdujeron hace poco, se asignan según } \\ \text { criterios de equidad (más en teoría que en la práctica). }\end{array}\end{array}$

Política laboral autónoma (NI y NL), con fijación de un sueldo medio indicativo Flexibilidad para la contratación en las escuelas

Contratación descentralizada (NL)

Negociación salarial y carrera administrativa centralizadas

Contratación descentralizada (NI y, en menor medida, NL)

Negociación salarial y carrera administrativa centralizadas

Contratación compartida entre el NC y el NI

Negociación salarial y carrera administrativa centralizadas

Contratación descentralizada (UP)

Negociación salarial y carrera administrativa centralizadas, con amplio margen de flexibilidad

Fuente: Elaboración propia basada en Carciofi, ed. (1996); Ruiz-Mier y Giussani (1997), Draibe (1998), Vargas y Sarmiento (1997 a y b), Ornelas (1997), Castillo (1998), Espinoza y Marcel (1994).

a $\mathrm{NC}=$ nivel central (gobierno central o federal); $\mathrm{NI}=$ nivel intermedio (estados, provincias o departamentos); $\mathrm{NL}=$ nivel local (municipios); UP=unidad de producción.

b Educación primaria.

c Solamente se considera la distribución del presupuesto del nivel central de educación básica (o sea, no se incluyen los recursos propios de los niveles subnacionales). No se incluyen, tampoco, los recursos de coparticipación.

d Educación total (incluye educación superior).

e El grado de descentralización moderado se debe principalmente a los recursos públicos destinados al sector privado subvencionado que permanecen centralizados. Faltan datos sobre los recursos regionales destinados a la inversión.

f Educación total (incluye educación superior). El grado de descentralización moderado se debe no solamente a la inclusión de la educación superior, sino también a la permanencia de un grado de centralización importante en la contratación de los recursos humanos y a la importancia de programas (por ejemplo, para el mejoramiento de la calidad educativa y el fomento de la ciencia y la cultura) que siguen centralizados.

g Educación total. Recursos descentralizados a municipios y escuelas. Incluye recursos propios generados por las escuelas. La escasa cobertura del proceso en 1996 explica el grado todavía bajo de descentralización presupuestaria. Faltan datos más actualizados. 
pan por lo menos dos niveles, incluido el nivel central, en la responsabilidad de todas las funciones, excepto en la gestión de capital y de funcionamiento de los establecimientos (o sea, la función de administración excluida la gestión de los recursos humanos); esto ilustra que no hay una simple dicotomía entre sistemas centralizados y descentralizados, sino más bien una variedad de opciones. De hecho, la única tendencia común aparente en todos los sistemas de suministro es el fortalecimiento del papel regulador del Estado, necesario en un sistema descentralizado, y el traspaso de la administración directa del servicio a niveles subnacionales. Dependiendo de la combinación de niveles por función, así como de los indicadores presentados en el cuadro $2,{ }^{20}$ es posible establecer el grado de autonomía efectivamente entregado a cada nivel subnacional en cada aspecto de la provisión e identificar, por último, el o los niveles que son receptores principales de la responsabilidad por los servicios, la magnitud de esta responsabilidad y su distribución entre niveles.

Haciendo un esfuerzo de síntesis, y considerando también el papel de la comunidad en los distintos aspectos de la provisión, ${ }^{21}$ es posible clasificar tentativamente los procesos analizados en cinco grandes tipos de reformas sobre la base de la clasificación presentada en la sección II, que hace hincapié en los aspectos de autonomía:

i) Procesos de "devolución” híbrida con poca participación en un nivel territorial principal, como el de provincialización en Argentina y los sistemas estaduales y municipales de provisión de educación primaria, que funcionan de manera paralela, en Brasil. En ambos países estos procesos, en primer lugar, entregan proporciones similares de recursos descentralizados a los niveles subnacionales (alrededor del 90\% de los recursos totales para educación primaria) y hacen la mayor parte -o la totalidad, en el caso argentinode los traspasos bajo la forma de transferencias generales (cuadro 2). En segundo lugar, por las proporciones de recursos que generan los niveles proveedores, que representan generalmente más del $40 \%$ de los recursos totales disponibles para educación; ${ }^{22}$ confieren

${ }^{20}$ Complementados en el texto con indicaciones sobre la proporción de recursos propios respecto de los recursos totales.

${ }^{21}$ Para evaluar esta dimensión se ha tomado en cuenta no solamente la existencia o no de canales de participación, sino también la efectiva utilización de estos por la comunidad.

${ }^{22}$ Excepto en el caso de los municipios brasileños, para los cuales las proporciones de recursos propios deben representar del 15 al $20 \%$ de los recursos totales. En el estado de Santa Catarina, por más autonomía financiera a los niveles proveedores que en otros casos, en grados que difieren según las directrices de utilización existentes; Argentina probablemente da mayor libertad de decisión al nivel intermedio, por cuanto las provincias argentinas — a diferencia de los estados y municipios brasileños - no están sujetas a norma alguna de utilización de los recursos propios y coparticipados. En tercer lugar, por tener un grado de autonomía casi total en la política laboral y muy importante en lo pedagógico-curricular. Con respecto a los mecanismos de participación, en ambos países los procesos no han sido participativos, o, por lo menos, las instancias existentes de participación no han funcionado de manera eficaz. En Brasil, sin embargo, el proceso de desconcentración escolar en curso, como se verá más adelante, está fomentando una participación activa dentro de las escuelas.

ii) Procesos de "devolución" híbrida participativa en la unidad de producción, o sea, del tipo principal/ agente entre un agente y dos principales (el nivel central y la comunidad) con una relación leve entre el agente y el nivel central, como el proceso de descentralización escolar en Nicaragua. El proceso nicaragüense, por el monto de recursos propios generados por las escuelas mismas (en promedio el $45 \%$ de los recursos totales a disposición de los centros de educación secundaria en 1996) y por el grado importante de autonomía que éstos tienen en la gestión del personal (nombramiento de directores, contratación y despidos, incentivos salariales) y en lo pedagógico-curricular, se acerca a un proceso de "devolución" híbrida, a pesar de tener mayores limitaciones de autonomía que en los casos de Argentina y Brasil. Puede, además, ser caracterizado como participativo por la importancia creciente de los consejos directivos en la administración de los centros escolares autónomos.

iii) Reformas de tipo principal/agente ${ }^{23}$ entre un principal (nivel central) y un agente (nivel intermedio o local) con poca participación (casos de Chile y México). En ambos casos estos procesos se caracterizan, ante todo, por una proporción similar de recursos propios (en promedio alrededor del 10\% de los recursos totales del nivel proveedor disponibles para educación), que limitan la responsabilidad financiera del nivel proveedor de los servicios, pero lo dejan en libertad de

ejemplo, en 1993 los municipios financiaban en promedio el 20\% del gasto educativo con recursos propios y el porcentaje va aumentando (FUNDAP, 1996)

${ }^{23}$ De ahora en adelante, el modelo principal/agente se refiere al modelo principal/agente de intensidad media definido en la sección II. 
asignar sus recursos sin sujeción a normas de gasto o asignación. Aproximadamente el 50 a $60 \%$ de los recursos destinados a la educación primaria y secundaria se manejan de forma descentralizada, y la totalidad — en Chile — o la mayor parte — en México — se traspasan bajo la forma de transferencias específicas (cuadro 2). La negociación salarial, así como los aspectos principales de la carrera docente, se mantienen centralizados y la responsabilidad por los contenidos educativos es compartida entre el nivel central y el nivel intermedio o local, siendo importante el papel del nivel central en la definición de los planes de estudio. ${ }^{24}$ Pese a ser el chileno un modelo de municipalización y el mexicano uno de estadualización, en ambos faltan mecanismos efectivos de participación local. En Chile, sin embargo, desde el principio de los años noventa se despliegan esfuerzos de traspaso de responsabilidades en las escuelas de todo el país, que deberían favorecer la participación. La utilización del subsidio por estudiante como mecanismo de asignación de los recursos en el país debería incentivar la participación de los padres a través de la elección del establecimiento escolar. Sin embargo, al entregarse el subsidio a la municipalidad y no a la escuela ni a las familias, éstas no se sienten involucradas en el proceso de asignación de los recursos y siguen percibiendo esta educación como gratuita (Carciofi, ed., 1996), reduciéndose así el aliciente para participar activamente en la elección y operación de las escuelas.

iv) Reformas de tipo principal/agente entre un principal (nivel central) y dos agentes (niveles intermedios y locales que funcionan de manera complementaria) y con poca participación, como los procesos de descentralización de Bolivia y Colombia. Estas reformas se caracterizan en primer lugar por un cofinanciamiento que involucra dos niveles, además del nivel proveedor (el municipio), con una proporción similar de recursos descentralizados (aproximadamente el $90 \%$ ) sujetos a directrices de utilización bastante restrictivas (cuadro 2). En segundo lugar, por un monto reducido de financiamiento con recursos locales (aproximadamente $5 \%$ en Bolivia y $10 \%$ en Colombia). En tercer lugar, por la gestión de la política laboral y de lo pedagógico-curricular compartida entre el nivel proveedor y al menos otros dos mismos niveles (caso de Colombia) o que depende de dos mismos niveles que no incluyen el nivel proveedor (caso de Bolivia). En estas formas de descentralización, la responsabilidad

\footnotetext{
${ }^{24}$ Cabe destacar que la administración de estas funciones es comparativamente más rígida en México que en Chile.
}

de la provisión está diluida entre tres niveles y puede dar lugar a problemas de responsabilidad, de coordinación entre niveles y de supervisión financiera. A pesar de que en ambos países se están impulsando mecanismos para involucrar a la comunidad local a través de la creación de órganos de participación y de que en Colombia hay un traspaso incipiente de responsabilidades a nivel escolar, la participación y el control social todavía siguen siendo débiles. En Colombia, se está discutiendo actualmente un cambio en las fórmulas para asignar los recursos, con miras a establecer un sistema de asignación por estudiante que haga más eficiente la provisión de servicios mediante un mayor involucramiento de los padres, entre otros arbitrios.

v) Procesos de desconcentración tendencialmente participativa en la unidad de producción, como es el caso de la descentralización escolar en Brasil. El traspaso de algunas categorías de recursos directamente a las escuelas, que se está haciendo desde la mitad de los años ochenta en las escuelas estaduales de muchos estados, combinado con el nombramiento de los directores por los consejos escolares y la participación de éstos en la gestión corriente y de contenido de los establecimientos, puede ser considerada como una desconcentración ya avanzada ${ }^{25}$ de responsabilidades en las unidades escolares, con un grado satisfactorio de participación de la comunidad escolar en el proceso educativo a través de los consejos.

En el gráfico 2 se ofrece una síntesis de la tipología de modelos de descentralización de la educación.

A partir de un análisis comparativo de estos modelos de reforma, en apariencia muy distintos entre ellos, se pueden detectar sin embargo algunas tendencias generales. En primer lugar, cualquiera sea el grado de descentralización del presupuesto y la naturaleza de las transferencias utilizadas, los niveles subnacionales siguen exhibiendo una alta dependencia financiera del nivel central, toda vez que la mayoría de los recursos aún proviene de éste, salvo en los sistemas estaduales de Brasil. En segundo lugar, en casi todos los países analizados persisten rigideces importantes en el área de recursos humanos, debidas principalmente a los estatutos de funcionario público que rigen los aspectos de negociación salarial y de carrera administrati-

\footnotetext{
${ }^{25}$ El ejemplo más acabado de este proceso es Minas Gerais donde, a principios de los años noventa, se adoptaron medidas combinadas para democratizar la gestión y para fortalecer la autonomía escolar en las áreas administrativa, financiera y pedagógica. Véase una descripción de este proceso en Guedes, Lobo y Walker (1997).
} 
GRAFICO 2

América Latina (siete países): Tipología de modelos de descentralización de la educación ${ }^{a}$

\begin{tabular}{|l|c|c|c|c|c|c|c|c|c|c|}
\hline & \multicolumn{3}{|c|}{ "Devolución" } & \multicolumn{3}{c|}{ Principal/Agente } & \multicolumn{3}{c|}{ Desconcentración } & $\begin{array}{c}\text { Grado de participación } \\
\text { de la comunidad }\end{array}$ \\
\hline & NI & NL & UP & NI & NL & UP & NI & NL & UP & \\
\hline Argentina & MH & & & & & & & & & Bajo \\
\hline Bolivia & & & & & & & & & & Incipiente \\
\hline Brasil & MH & MH & & & & & & & & Medio (UP) \\
\hline Chile & & & & & & & & & AI & Bajo/En aumento \\
\hline Colombia & & & & & & & & & AI & Bajo/En aumento \\
\hline México & & & & & & & & & & Bajo \\
\hline Nicaragua & & & MH & & & & & & & Medio/En aumento \\
\hline
\end{tabular}

Fuente: Elaboración propia.

a $\mathrm{NI}=$ Nivel intermedio (provincia, estado o departamento)

$\mathrm{NL}=$ Nivel local (municipios)

$\mathrm{MH}=$ Modelo híbrido

$\mathrm{AI}=$ Autonomía incipiente.

$\mathrm{UP}=$ Unidad de producción (escuela)

va; tales rigideces reducen mucho el grado de autonomía en la provisión del servicio (en todos los modelos la función pedagógico-curricular suele exhibir más autonomía). En tercer lugar, la participación de la comunidad en las decisiones sobre las distintas funciones de la provisión de servicios educativos — salvo en Nicaragua y algo menos en Brasil- es baja, aunque creciente en algunos casos. En cuarto lugar, y vinculada con la escasa participación, destaca la relativa ausencia de la escuela como actor importante en la toma de decisiones. En casi todos los países, las refor- mas tienden a traspasar las responsabilidades a los niveles intermedios y/o locales y hacen que las escuelas pasen a depender de ellos en lo financiero, lo administrativo y lo pedagógico. Sólo en Brasil y, sobre todo, en Nicaragua, la escuela ha adquirido un papel central dentro del sistema. Como se señaló más atrás, en estos últimos años se inició la entrega gradual de responsabilidades pedagógico-curriculares a la escuela en Chile y Colombia; sin embargo, estas medidas deben ir acompañadas por una mayor autonomía administrativa para que sean realmente eficaces.

\section{IV}

\section{Breve análisis de los principales resultados $y$ tendencias de las reformas}

La posibilidad de evaluar una reforma depende de su horizonte temporal, de su profundidad y de la disponibilidad de información confiable para hacer el seguimiento de sus resultados; por lo tanto, varía de un país a otro, lo que complica notablemente el análisis comparativo de resultados. Además, la naturaleza misma de una reforma descentralizadora, que es generalmen- te gradual en el tiempo, muy compleja y se da en una gran heterogeneidad espacial, dificulta de todos modos la tarea de evaluación. Finalmente, como la mayoría de los episodios aquí analizados sucedieron a principios de los años noventa, no hay aún un horizonte temporal suficiente para efectuar una verdadera evaluación. De hecho, por lo reciente de la mayoría de las 
experiencias, solamente los casos de Chile, Argentina y Brasil se prestan a una evaluación, aunque incompleta, de sus resultados; en los otros casos sólo es posible identificar algunas tendencias iniciales. La evaluación ha de centrarse en el efecto de las reformas sobre la eficiencia y la equidad de la provisión de los servicios educativos. Como se vio en la sección II, se supone que una reforma de descentralización debería actuar positivamente sobre la eficiencia, pero que la equidad, en cambio, podría verse en riesgo.

Sobre la base de la información presentada en la sección III y la información específica relativa a cada uno de los países analizados, ${ }^{26}$ se puede intentar el siguiente balance, muy simplificado en beneficio de la comparabilidad:

i) El escaso avance que se ha logrado en materia de participación en la mayoría de los países no ha permitido aprovechar realmente las potencialidades de las reformas para contribuir a elevar la eficiencia social. ${ }^{27}$ En todos los países hay canales de participación más o menos específicos, pero en pocos han sido eficaces. Lo que ha tenido mayor influencia en el grado de eficacia logrado han sido las motivaciones iniciales de las reformas. De hecho, en Nicaragua, y, en menor medida, en Brasil y en Bolivia se registran los mayores avances en materia de participación y esto tiene que ver con la importancia de los objetivos de democratización en estos países. También han influido el grado de autonomía financiera de los nuevos niveles proveedores y el grado de autonomía de las unidades productoras (como lo demuestran los casos de Brasil y Nicaragua).

ii) Se cuenta con pocos datos sobre la evolución de la eficiencia técnica de la provisión de servicios educativos, medida a través de indicadores de costoimpacto,${ }^{28}$ por lo reciente de la mayoría de las refor-

\footnotetext{
${ }^{26}$ Extraída de Carciofi, ed. (1996), Ruiz-Mier y Giussani (1997), Draibe (1998), Vargas y Sarmiento (1997 a y b), Ornelas (1997), Castillo (1998) y Di Gropello (1997).

${ }^{27} \mathrm{La}$ ausencia de información directa al respecto, causada por la falta de encuestas repetidas en el tiempo sobre la satisfacción de los usuarios, limita las posibilidades de evaluación, cualquiera sea el horizonte temporal, al análisis de indicadores de participación de la comunidad en las decisiones de provisión de servicios. Se supone que un grado de participación satisfactorio es condición previa para lograr un grado de eficiencia social satisfactorio.

28 Para medir directamente la eficiencia técnica se utilizan indicadores de costo-impacto, en los cuales el impacto se estima por el efecto sobre la cobertura (medida, por ejemplo por la tasa de escolarización) y la calidad (por la tasa de repetición o el rendimiento académico) y el costo, medido por indicadores de gasto o insumos. La dificultad de comparar numeradores y denominadores que se expresan en unidades de medida diferentes y de establecer una relación de causalidad con la reforma que se analiza, sugiere interpretar con cuidado este tipo de indicadores.
}

mas analizadas o por la falta de información. Solamente en los casos de Argentina, Brasil y Chile existe alguna información de largo plazo acerca de la evolución de indicadores de este tipo (resumida en el cuadro 3). En general, esa evolución ha sido ambigua en todos los casos en los cuales se ha traspasado la responsabilidad principal de la provisión a niveles subnacionales de gobierno (intermedios y/o locales). En los tres países mencionados, por ejemplo, la cobertura y el gasto han exhibido trayectorias crecientes o decrecientes de igual magnitud y faltan datos sobre la evolución de indicadores de costo-calidad. De todas maneras, no parece que las reformas hayan sido acompañadas por mejoras tangibles en la productividad del gasto. Se destaca, en cambio, una evolución tendencialmente positiva en los casos de descentralización de la provisión en las escuelas, como se ha observado en el estado brasileño de Minas Gerais y, aunque se trata de una experiencia más reciente y por lo tanto más difícil de evaluar, en Nicaragua. ${ }^{29} \mathrm{~A}$ falta de indicadores de costo-impacto, o con miras a complementarlos, es posible identificar señales positivas o negativas para la eficiencia, usando datos sobre eventuales cambios en la asignación y utilización de los recursos, la existencia o inexistencia de condiciones previas de capacitación, el desarrollo institucional y la regulación necesarias para el éxito de las reformas, la autonomía entregada a los niveles subnacionales y los mecanismos existentes para fomentar la eficiencia. En general, se observan algunas tendencias positivas, como algunos aumentos de la inversión (Bolivia, Colombia), pero también algunos problemas en el uso y asignación de los recursos: por ejemplo, casos de mala utilización de la infraestructura (Bolivia) o de excesivo gasto en personal (Nicaragua, Chile), generados por deficiencias en el diseño y aplicación de los modelos.

iii) Con respecto a la equidad territorial, también hay poca información sobre la evolución de la distribución territorial de los resultados educativos y su relación con las reformas. Los análisis disponibles se centran generalmente en la distribución de los recursos y el gasto entre las áreas geográficas, generada por las reformas, como indicador intermedio de equidad. ${ }^{30} \mathrm{En}$

\footnotetext{
29 Según una encuesta reciente (Banco Mundial, 1996), es opinión compartida por los distintos actores que en la enseñanza secundaria mejoró el nivel académico en los centros que se volvieron autónomos. Sin embargo, sería necesario cuantificar este resultado y compararlo con la magnitud de los recursos generados por los copagos para extraer conclusiones acerca de la productividad del gasto.

${ }^{30}$ Se supone que una distribución progresiva del gasto debería permitir mejorar los resultados.
} 
CUADRO 3 América Latina (siete países): Resultados en materia
de eficiencia y equidad derivados de algunas de las reformas

\section{País}

Argentina

Entre 1980 y 1991, la tasa neta de escolarización primaria aumentó $6.6 \%$ y el porcentaje de población de 5 a 9 anos que nunca asistió a un establecimiento escolar disminuyó $70 \%$. Sin embargo, el gasto educativo en educación primaria aumentó $85 \%$ entre el subperíodo 1970/1977 y el subperíodo 1978/1985. En conclusión, es ambigua la evolución de los indicadores de costo-cobertura de la provisión de servicios educativos. Además, faltan mediciones repetidas en el tiempo de la calidad de la educación impartida, así que no se sabe cómo evolucionaron los indicadores de costocalidad.

Brasil

Entre 1982 y 1995 la tasa neta de escolarización primaria aumentó $23 \%$. Sin embargo, el gasto real per cápita en educación primaria aumentó $23 \%$ entre el subperíodo $1980 /$ 82 y 1983/90, así que es ambigua la evolución de la eficiencia de la provisión de servicios. Además, no se cuenta con mediciones directas de calidad para conocer la evolución de los indicadores de costo-calidad.

En algunos estados pueden haber mejorado los indicadores de costo-cobertura y costo-calidad. Por ejemplo, en el estado de Minas Gerais: a partir de la reforma de 1991, que profundizó la autonomía escolar, han mejorado los resultados de las pruebas de rendimiento académico (aumento de 20 puntos en idioma portugués y de 40 en matemática entre 1992 y 1994), la condición de la infraestructura y la capacitación de los docentes, a paridad de gasto.

Chile

Frente a una caída del gasto per cápita en educación básica de $26 \%$ entre 1981 y 1990 , la matrícula del sector municipal se redujo $23 \%$ en el mismo período, mientras que la matrícula del sector privado subvencionado ${ }^{\mathrm{d}}$ aumentó $73 \%$.

Además:

$R_{p}-R_{m}(1992)=6$ puntos $^{\mathrm{f}}$

Esto ilustra la escasa capacidad de gestión de las escuelas públicas con respecto a las privadas subvencionadas, a pesar de la municipalización.

\section{Equidad}

Después del traspaso, se triplicó la dispersión en los niveles de sueldo medio de los docentes de enseñanza primaria, en favor de las provincias con niveles de ingreso más elevado:

$\sigma_{s}(1983)=13^{\mathrm{a}} ; \sigma_{s}(1992)=39 \mathrm{y} r_{s, p i b}(1992)=0.6^{\mathrm{b}}$

Esta evolución, combinada con los ajustes en los planteles docentes efectuados por cada provincia (hacia una mayor convergencia del número de docentes por alumno) genera una distribución tendencialmente regresiva del gasto por alumno en educación primaria (gráfico 3):

$r_{\text {gep }, 1 / p i b}(1995)=-0.3$

y posiblemente ha llevado a un aumento de la dispersión de la calidad educativa ${ }^{\mathrm{c}}$ entre áreas.

Se nota un aumento de la dispersión de la calidad educativa entre áreas, como comprobado por el aumento de la dispersión en la proporción de docentes con primaria incompleta entre regiones:

$\sigma_{d p i}(1980)=39 ; \sigma_{d p i}(1994)=63$

que se relaciona con el continuo aumento de la dispersión en los niveles de sueldo medio docente, después de la liberalización del mercado laboral.

La evolución de la dispersión en los sueldos, combinada con los ajustes en los planteles docentes efectuados por cada municipio, genera una distribución regresiva del gasto por alumno en educación en el sector municipal (gráfico 4) :

$r_{\text {gem, }, 1 / p i b}(1990)=-0.6$

A pesar de la correlación positiva entre aportes municipales y capacidad fiscal de los municipios, ${ }^{\mathrm{e}}$ los efectos de la descentralización sobre la equidad territorial han sido limitados, presentándose de hecho desigualdad en el gasto por estudiante en educación (calculado como suma de los aportes municipales y de la subvención escolar central) sólo con respecto a un conjunto reducido de comunas de altos ingresos. Agregando los programas compensatorios de gasto implementados a partir de principios de los años noventa, se obtiene incluso una distribución levemente progresiva del gasto, con respecto a la distribución de la pobreza por municipio:

$r_{g e, p}(1994)=0.4$

Fuente: Elaboración propia basada en Carciofi, ed. (1996); Porto y Sanguinetti (1996), Draibe (1998), Guedes, Lobo y Walker (1997), Paes de Barros, Pinto de Mendonça y Shope (1993) y Winkler y Rounds (1993).

a $\sigma$ es la desviación estándar. Calculada a base de índices para comparabilidad entre los países.

b $r$ es el coeficiente de correlación $\left(r_{x, y}=\operatorname{Cov}(x, y) / \sigma_{x}, \sigma_{y}\right)$.

c En la medida en que los sueldos medios más elevados atraen a las personas más capacitadas y tienen un impacto positivo sobre la asistencia y motivación de los docentes, se puede esperar una relación positiva entre niveles de sueldo y calidad educativa.

d Las reformas de principios de los años ochenta en Chile incentivaron también la privatización al entregar los mismos subsidios públicos a las escuelas privadas y públicas. La existencia de las escuelas privadas subvencionadas es un punto de referencia muy útil para medir la eficiencia de las escuelas municipales.

e En 1993, en términos del gasto en educación por estudiante, el decil más rico aportaba cuatro veces más a la educación que el decil más pobre (Winkler, 1994).

f $\mathrm{Rm}=$ resultado educacional del sector municipal; $\mathrm{Rp}=$ resultado educacional del sector privado subvencionado. La diferencia positiva de rendimientos a favor de las escuelas privadas subvencionadas se mantiene también después de haber tomado en cuenta el sesgo socioeconómico. 
los únicos dos casos en que se dispone de datos comparativos en dos momentos suficientemente alejados entre sí —en Argentina y en Brasil- hay indicios de que la dispersión de la calidad del servicio entre áreas probablemente ha aumentado. En ambos países esto se relaciona con la inequidad en la distribución de los recursos entre áreas, en el marco de los modelos de "devolución" híbrida aplicados, lo que ha aumentado la dispersión de indicadores intermedios de la calidad educativa (sueldos, formación docente). En los demás países, sólo se dispone de información sobre la distribución territorial de recursos o gastos posterior a la reforma, sin comparaciones temporales, con el solo fin de detectar el grado de progresividad o regresividad de la distribución. En tres de los siete países (Argentina, Brasil y México) se observa una correlación tendencialmente regresiva entre el gasto y los niveles de ingreso o pobreza (gráficos 3, 4 y 6), En otros dos (Colombia y Nicaragua) hay una falta de correlación entre las transferencias intergubernamentales y los niveles de desarrollo de cada área (gráficos 5 y 7) que igualmente debería llevar a una distribución territorial del gasto regresiva, por la combinación de esta falta de correlación con la distribución regresiva de los recursos subnacionales. Solamente en Chile se observa una distri-

GRAFICO 3

Argentina: Relación entre el PIB y el gasto por alumno en educación primaria, 1995

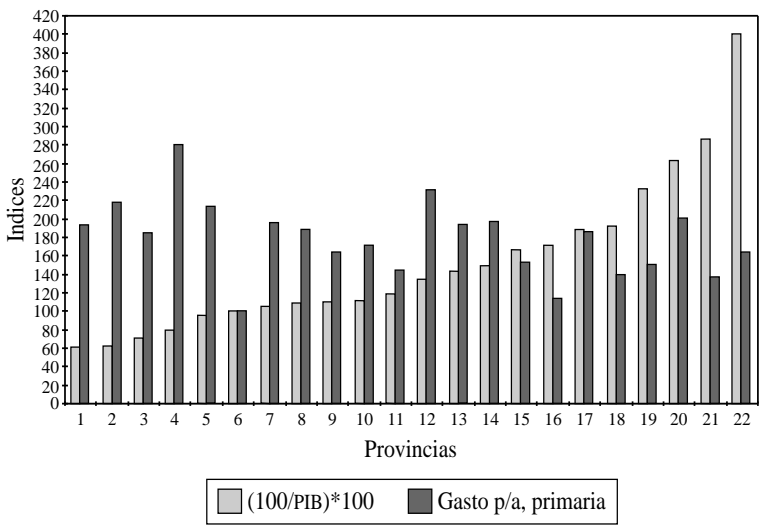

Fuente: Elaboración propia basada en Porto y Sanguinetti (1996) y Bisang y Cetrángolo (1997). bución levemente progresiva del gasto (cuadro 3), que se relaciona con los mecanismos de asignación y compensación aplicados en este país.
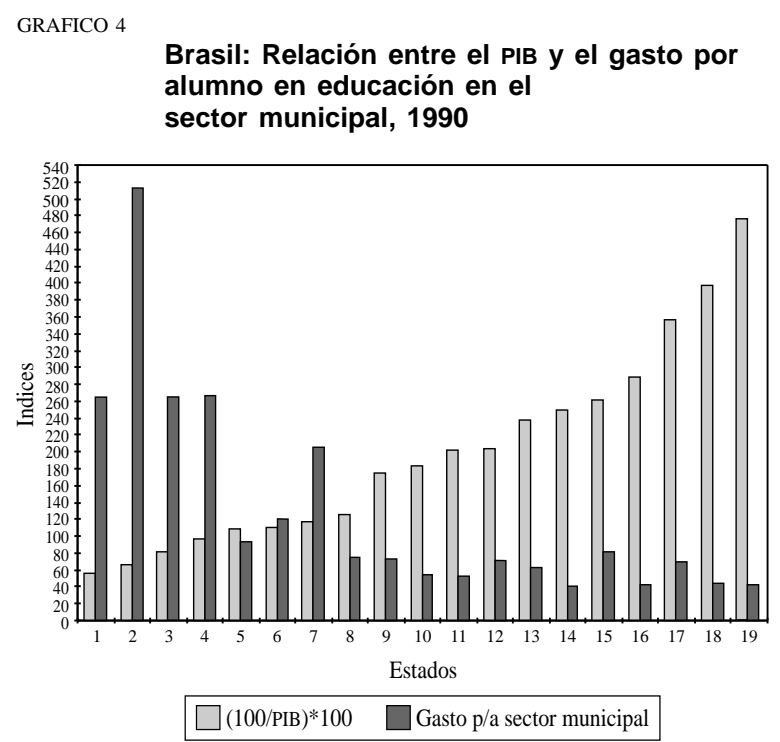

Fuente: Elaboración propia basada en Paes de Barros, Pinto de Mendonça y Shope (1993).

GRAFICO 5

Colombia: Relación entre la pobreza y la participación en los ingresos corrientes de la nación p/c, 1996

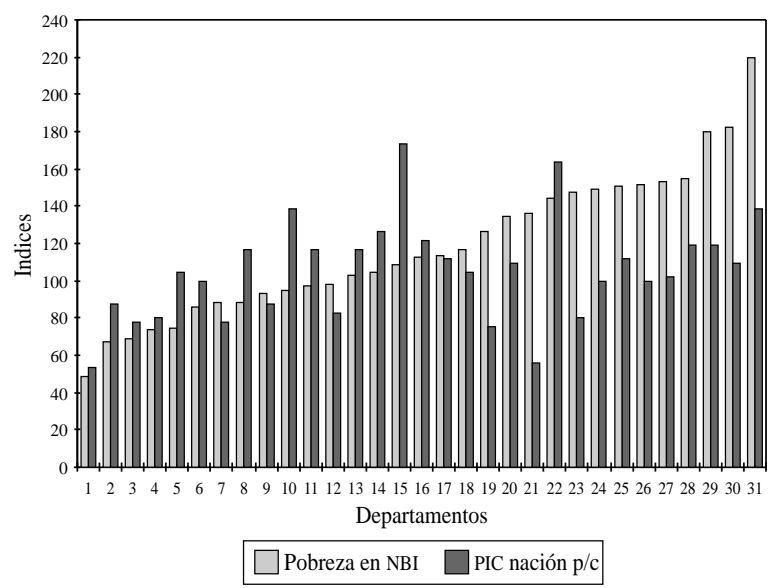

Fuente: Elaboración propia basada en Vargas y Sarmiento (1997a). 
GRAFICO 6

México: Relación entre la pobreza

y el gasto federal por alumno

en educación básica, 1995-1996

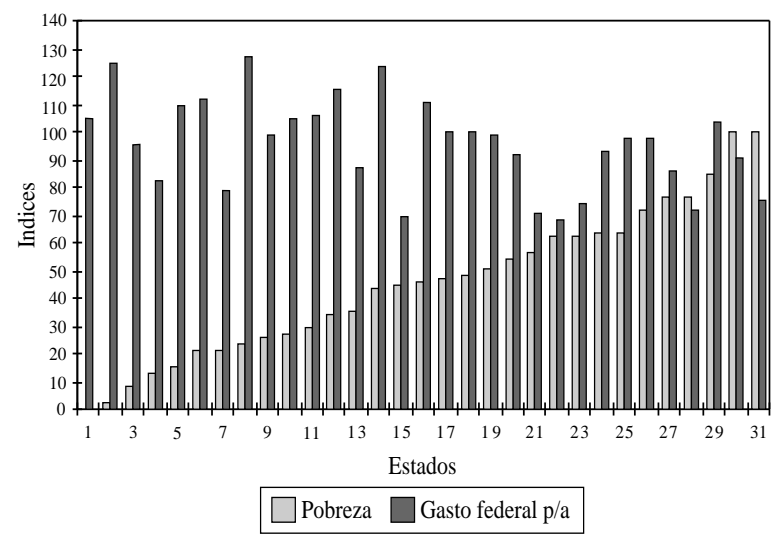

Fuente: Elaboración propia basada en México, Secretaría de Educación Pública (1996) y en el Banco Mundial (1992).
GRAFICO 7 Nicaragua: Relación entre la pobreza
y las transferencias $\mathrm{p} / \mathrm{c}$ del gobierno central en educación, 1996

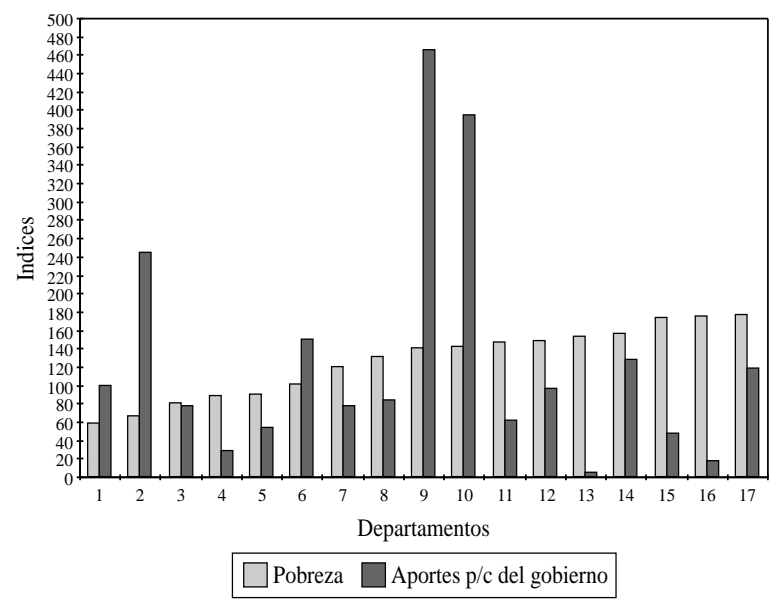

Fuente: Elaboración propia.

\section{V}

\section{Algunas lecciones para el diseño de modelos de reforma}

¿Qué se puede concluir de este rápido balance? No es fácil sacar conclusiones, pero la evaluación efectuada ha puesto en evidencia que los resultados de eficiencia y equidad de más largo plazo de las reformas no han sido, por lo general, muy satisfactorios, pues muestran escasos avances en la eficiencia social de la provisión de servicios educativos y en la productividad del gasto y los indicadores de calidad tienden a ser divergentes. Por otra parte, las tendencias más recientes son ambiguas. Con todo, queda claro que estos resultados se deben principalmente a problemas de diseño e implementación de las reformas, que pueden resolverse.

A continuación, se intenta reseñar algunas enseñanzas ${ }^{31}$ acerca del diseño de los modelos de reforma que surgen del análisis efectuado:

i) Es necesario entregar un grado de autonomía real a los nuevos niveles proveedores, minimizando el número de restricciones directas. Los escasos avances

${ }^{31}$ Por cierto, ellas deben ser calibradas según las condiciones socioeconómicas y político-administrativas iniciales de cada país. de Chile, por ejemplo, en el terreno de la eficiencia, se deben en gran parte a las rigideces del modelo que se aplica. Por otro lado, la falta de flexibilidad laboral, común en muchos países, es un freno para alcanzar metas más altas de eficiencia.

ii) La coherencia interna de los modelos es fundamental para los resultados, particularmente en lo que se refiere a la claridad en el diseño de las responsabilidades asignadas a cada nivel y a la existencia de mecanismos efectivos de coordinación. Esto es incluso más importante en los modelos que se basan en la corresponsabilidad de dos o más niveles. En estos casos es fácil que haya ineficiencia en la utilización de los recursos (por ejemplo, en Bolivia, donde las decisiones que afectan la relación inversión/gasto corriente no están coordinadas, generando problemas de inversión excesiva con respecto a la disponibilidad de personal).

iii) Un punto crucial para el éxito de las reformas lo constituye el diseño e implementación de las transferencias financieras intergubernamentales. Como ya fue mencionado en el contexto de una reforma de des- 
centralización, la permanencia de un monto de financiamiento central significativo que sea distribuido entre los niveles subnacionales según criterios socioeconómicos es una garantía para la preservación de la equidad, potencialmente en riesgo con la reforma. Por otro lado, en condiciones de escasa participación y capacitación, las transferencias del nivel central pueden contribuir de manera importante a estimular opciones eficientes desde el punto de vista técnico, fiscal y social. Considerando las peculiaridades de los agentes (los nuevos niveles proveedores) y del principal (el nivel central), este último debería garantizar un nivel mínimo de financiamiento a todos los niveles subnacionales, proporcional a las condiciones socioeconómicas iniciales de partida y a los costos de producción locales (ajuste por equidad), y complementarlo con un financiamiento adicional vinculado a criterios de eficiencia (asignación según resultados en materia de cobertura o calidad de los servicios). Para minimizar los problemas de selección adversa y riesgo moral que se plantean en situaciones de información asimétrica y objetivos diferentes entre agentes y principal, es necesario, sin embargo, que el nivel central ponga en marcha un sistema eficiente de supervisión que permita verificar el esfuerzo de los agentes por alcanzar las metas de producción y facilitar las asignaciones según eficiencia, y por otra parte, que estimule la recolección y transmisión a los niveles superiores de información sobre la situación socioeconómica de las áreas atendidas por los nuevos niveles proveedores, con el fin de facilitar las asignaciones según equidad. De no ser así, las intervenciones del nivel central —el supuesto remedio- podrían ser tanto o más dañinas que la enfermedad.

Ahora bien, al revisar la naturaleza y los criterios de asignación de las transferencias utilizadas en las reformas de primera generación, llama la atención en primer lugar que — salvo en Chile - tienen poca relevancia las transferencias específicas, aunque ellas resultan más apropiadas que las generales para responder a las exigencias sectoriales y son necesarias para vincular los recursos a indicadores de eficiencia. En segundo lugar, destaca la ausencia de criterios y/o directrices de asignación que tomen en cuenta la equidad y la eficiencia técnica. ${ }^{32}$ Esto explica en parte los resultados generalmente poco satisfactorios de eficiencia y equidad observados en estos países. En cuanto a

\footnotetext{
${ }^{32}$ Aunque en Brasil se introdujeron recientemente criterios de asignación que incorporan aspectos de eficiencia y equidad.
}

las reformas de segunda generación, casi todas intentan incorporar estos criterios de manera explícita mediante fórmulas más o menos complejas y directrices de gasto o asignación. Sin embargo, hay casos (Colombia, Nicaragua) en que las debilidades del marco regulador y la falta de información hacen difícil aplicar los criterios de equidad, lo que contribuye a la falta de correlación entre las transferencias y los niveles de pobreza. Para que una estructura de incentivos funcione es importante también contar con mercados laborales flexibles y autonomía real para que los niveles receptores de los servicios puedan responder eficazmente a los estímulos.

El traspaso de las principales competencias a un nivel intermedio o a agrupaciones de municipios (dependiendo del tamaño y densidad poblacional de las divisiones geográficas del país), combinado con la descentralización de funciones administrativas, de contenidos y financieras en las escuelas, debería permitir maximizar la eficiencia y preservar la equidad. En particular, los enfoques municipalistas aplicados en muchos países generan pérdida de economías de escala que una descentralización a un nivel superior debería poder evitar. Las ganancias en materia de eficiencia técnica y social pueden ser maximizadas con la entrega de márgenes significativos de autonomía a las unidades productoras, como sugieren las experiencias positivas de Brasil y los resultados preliminares de Nicaragua.

Es fundamental contar con un marco regulador adecuado a las exigencias de regulación y supervisión de un sistema descentralizado de provisión de servicios educativos. Este marco debería involucrar al nivel central, así como a los niveles intermedios y locales.

Aumentar la participación y el control social es otro gran desafío de la reforma. Las motivaciones iniciales de democratización y la entrega de más autonomía a las unidades productoras deberían tener efectos positivos sobre estos aspectos.

La reforma debe ir acompañada de medidas y programas de capacitación específicos, sobre todo en los aspectos de gestión. La falta de habilidades técnicas y administrativas ha tenido efectos adversos en los resultados de Brasil y es un problema particularmente serio para Bolivia y Nicaragua.

Por lo demás, dadas las necesidades de información para el funcionamiento del sistema, es preciso contar con bases locales de información actualizada y con canales efectivos para transmitirla.

En conclusión, las reformas más recientes han traído algunos efectos favorables, como los esfuerzos 
por reducir la arbitrariedad en la asignación de las transferencias y por crear canales de participación más eficaces y también los enfoques menos municipalistas. Algunos de estos elementos han sido posteriormente incorporados en las reformas iniciadas hace más tiempo. Sin embargo, persisten algunos problemas cuya solución constituye un desafío importante para las reformas de tercera generación: la escasa autonomía real en algunas funciones, particularmente en la gestión de los recursos humanos; el desarrollo todavía escaso de los marcos reguladores para aplicar correctamente las fórmulas de asignación y la supervisión de los sistemas de provisión de servicios; la elección de modelos de provisión difíciles de coordinar y regular; la falta de autonomía de las unidades productoras de los servicios; la falta de sistemas actualizados de información, y los insuficientes esfuerzos de capacitación para encarar las nuevas exigencias en la provisión de los servicios.

\section{Bibliografía}

Banco Mundial (1992): Mexico: The Initial Education Strategy, Informe, $\mathrm{N}^{\mathrm{o}}$ 10129-ME, Washington, D. C.

(1996): Nicaragua's School Autonomy Reform: A First Look, serie Impact evaluation of education reforms, $\mathrm{N}^{\mathrm{o}} 1$, Washington, D. C.

Bisang, R. y O. Cetrángolo (1997): Descentralización de los servicios de salud en la Argentina, serie Reformas de política pública, $\mathrm{N}^{\circ} 47$, Santiago de Chile, Comisión Económica para América Latina y el Caribe (CEPAL).

Carciofi, R. ed. (1996): Desafíos de la descentralización: educación y salud en Argentina y Chile, Santiago de Chile, CEPAL.

Castillo, M. (1998): La descentralización de los servicios de educación en Nicaragua, serie Reformas de política pública, $\mathrm{N}^{\circ}$ 53, Santiago de Chile, CEPAL.

Chile, MINEDUC (Ministerio de Educación Pública) (1996a): Objetivos fundamentales y contenidos mínimos obligatorios de la Educación Básica chilena, Santiago de Chile. (1996b): Modificación de la Ley $N^{\circ} 19.070$ que aprobó el Estatuto Docente, Santiago de Chile, septiembre.

Di Gropello, E. (1997): Descentralización de la educación en América Latina: un análisis comparativo, serie Reformas de política pública, $\mathrm{N}^{\circ} 57$, Santiago de Chile, CEPAL.

Draibe, S. M. (1998): Avaliação da Descentralização das Políticas Sociais no Brasil: Saúde e Educação Fundamental, serie Reformas de política pública, $\mathrm{N}^{\circ} 52$, Santiago de Chile, CEPAL.

Espínola, V. (1995): El impacto de la descentralización sobre la educación gratuita en Chile, serie Gestión escolar, $\mathrm{N}^{\circ} 1$, Santiago de Chile, Centro de Investigación y Desarrollo de la Educación (CIDE).

Espinoza, J. y M. Marcel (1994): Descentralización fiscal: el caso chileno, serie Política fiscal, $\mathrm{N}^{\circ}$ 57, Santiago de Chile, CEPAL.

Fiske, E. (1996): Decentralization of Education: Politics and Consensus, Washington, D.C., Banco Mundial.

FUNDAP (Fundación de Desarrollo Administrativo) (1996): Federalismo no Brasil: descentralização e políticas sociais, São Paulo.

Guedes, A., T. Lobo y R. Walker (1997): Gestión descentralizada de la educación en el Estado de Minas Gerais, Brasil, Informe, $\mathrm{N}^{\mathrm{o}} 11$, Washington D.C., Banco Mundial.

Hart, O. y B. Holmstrom (1987): The theory of contracts, Advances in Economic Theory, Fifth World Congress, Londres, Cambridge University Press.

Hevia, R. (1991): Política de descentralización en la educación basica y media en America Latina: estado del arte, Santiago de Chile, Organización de las Naciones Unidas para la Educación, la Ciencia y la Cultura (UNESCO)/Red Latinoamericana y del Caribe de Información y Documentacion en Educación (REDUC).
IPEA (1994): Gestão escolar: desafios e tendencias, serie Gestión escolar, $\mathrm{N}^{\circ} 145$, Brasilia.

Klugman, J. (1994): Decentralization: A Survey of Literature from a Human Development Perspective, Occasional Paper, $\mathrm{N}^{\circ} 13$, Nueva York, CEPAL, Oficina del Informe Nacional de Desarrollo Humano

Kreps, D. (1990): A course in Microeconomic Theory, Princeton, New Jersey, Princeton University Press.

México, Secretaría de Educación Pública (1996): Informe de labores 1995-1996, México, D. F.

Ornelas, C. (1997): El proceso de descentralización de los servicios de la educación en México, Santiago de Chile, CEPAL.

Paes de Barros, R., R.S. Pinto de Mendonça y J.A. Shope (1993): Regional Disparities in Education within Brazil: The Role of Quality of Education, Texto para discussão, No 311 , Brasilia, Instituto de Investigación Económica Aplicada (IPEA).

Porto, A. y P. Sanguinetti (1996): Las transferencias intergubernamentales y la equidad distributiva: el caso argentino, serie Política fiscal, $\mathrm{N}^{\circ} 88$, Santiago de Chile, CEPAL.

Rasmusen, E. (1989): Games and Information. An Introduction to Game Theory, Oxford, Reino Unido, Basil Blackwell.

Rees, R. (1985a): The theory of principal and agent: Part 1, Bulletin of Economic Research, vol. 37, $\mathrm{N}^{\mathrm{o}} 1$.

(1985b): The theory of principal and agent: Part 2, Bulletin of Economic Research, vol. 37, $\mathrm{N}^{\circ} 2$.

Rondinelli, D., J. Nellis y G. S. Cheema (1983): Decentralization in Developing Countries: A Review of Recent Experience, Staff working paper, $\mathrm{N}^{\circ} 581$,Washington, D. C., Banco Mundial.

Ruiz-Mier, F. y B. Giussani (1997): El proceso de descentralización y el financiamiento de los servicios de educación y salud en Bolivia, serie Reformas de política pública, $\mathrm{N}^{\circ} 48$, Santiago de Chile, CEPAL.

Vargas, J. E. y A. Sarmiento (1997a): Características de la descentralización colombiana, serie Reformas de política pública $\mathrm{N}^{\circ}$ 49, Santiago de Chile, CEPAL.

(1997b):La descentralización de los servicios de educación en Colombia, serie Reformas de política pública, $\mathrm{N}^{\circ} 50$, Santiago de Chile, CEPAL.

Winkler, D. (1991): Decentralization in Education: An Economic perspective, Washington, D.C., Banco Mundial, Departamento de Población y Recursos Humanos.

(1994): The Design and Administration of Intergovernmental Transfers: Fiscal Decentralization in Latin America, Discussion papers, $\mathrm{N}^{\circ} 235$, Washington, D.C., Banco Mundial.

Winkler, D. y T. Rounds (1993): Municipal and Private Sector Response to Decentralization and School Choice: The Case of Chile, 1981-1990, Human Resources and Operations Policy Working Papers, $\mathrm{N}^{\circ}$ 8, Washington, D.C., Banco Mundial. 